Human Health

\title{
Determination of social support status and risk of mental illness in patients using multiple drugs in primary care
}

Tugba OZER ${ }^{1}$, Kenan TOPAL ${ }^{2}$, Cigdem GEREKLIOGLU ${ }^{3}$, Huseyin AKSOY²

${ }^{1}$ Sekseninciyil Family Health Center, Adana, TURKEY

2 University of Health Sciences, Adana City Training and Research Hospital, Department of Family Medicine, Adana, TURKEY

${ }^{3}$ Cukurova University Faculty of Medicine, Department of Family Medicine, Adana, TURKEY

\section{ABSTRACT}

Aim: Multiple drug use (polypharmacy) increases the risk of numerous negative health consequences. The aim of this study was to examine the factors that may lead to polypharmacy in adult patients followed in primary care and to determine the social support status and anxiety-depression risk in patients using multiple drugs.

Methods: This cross-sectional study was conducted with 3 family medicine units in the Adana province. A total of 393 adult patients who were receiving two or more drugs daily were included. Sociodemographic data were recorded and risk factors for polypharmacy were questioned. The Multidimensional Scale of Perceived Social Support (MSPSS) and the Hospital Anxiety Depression Scale (HADS) were applied.

Results: Out of 393 participants, $52.9 \%$ were female and the mean age was $60.1 \pm 11.0$ years. The mean number of chronic diseases was $2.7 \pm .2$. The mean number of drugs used was $4.7 \pm 2.2$. Of the participants, $31.3 \%$ had risk of depression and $24.2 \%$ had risk of anxiety. The number of drugs used increased as age, body mass index (BMI), waist circumference and number of chronic diseases increased. The MSPSS total score decreased as age increased. The risk of anxiety and depression was significantly greater in women, participants with low education and those who had no partner.

Conclusions: Significant physical and mental problems occur in individuals who use multiple drugs, especially in the elderly. The present study revealed that predictors of polypharmacy include age, BMI, waist circumference and number of chronic diseases. Primary care physicians should be aware of these predictors when prescribing additional medication.

Keywords: Polypharmacy, Social Support, Anxiety, Depression

Corresponding Author: Kenan TOPAL kenantopal@gmail.com

Received: December 08, 2021; Accepted: December 15, 2021; Published Online: December 31, 2021

Cite this article as: Ozer, T., Topal, K., Gereklioglu, C. \& Aksoy, H. (2021). Determination of Social Support Status and Risk of Mental Illness in Patients Using Multiple Drugs in Primary Care. European Journal of Human Health 1(3), 88-97. 


\section{Introduction}

Polypharmacy is a severe global health concern $(1,2)$. Despite the absence of a standard definition for polypharmacy, the definition widely used in the literature is the regular use of at least five medications. The term polypharmacy may also be suggested as more drugs are prescribed and taken than are warranted clinically, or multiple drugs are used or one drug is used unnecessarily (3-5). Although polypharmacy is mostly a problem for the elderly, younger adults with chronic pain, such as fibromyalgia, or with developmental disabilities, especially those with additional chronic medical conditions, may experience polypharmacy. Besides, diabetes, heart disease, stroke, and cancer are the factors that lead to multi-drug use in younger adults (6-8). Polypharmacy has negative consequences for patients and the health care system. While decreased quality of life, increased mobility issues, increased mortality, increased risk of adverse drug events, disability, falls, frailty, inappropriate medication use, long-term care placement, medication non-adherence, increased use of the health care system (clinic visits, emergency department visits, hospitalizations) may be listed as the negative consequences of polypharmacy for patients; decreased physician functionality (workflow impairment, decreased quality of care), decreased physician productivity, increased burden on the health care system and increased medication errors are among its negative consequences for health care system. Being elderly, cognitive impairment, developmental disability, frailty, mental health conditions, multiple chronic conditions, residing in a long-term care facility, seeing multiple subspecialists may be suggested as the patient-related risk factors for polypharmacy (7). The increasing number of the drugs increases the risk of morbidity and mortality through the side effects and drug interactions. The increase in the number of drugs, when combined with treatment failure, brings additional burdens to health care providers and higher costs to health insurances. Besides, the number of potential drug-drug and drugdisease interactions rises exponentially with the number of drugstaken, possibly leading to therapy failure, worsening conditions, and reinforced effects. The excessive branching in medical practice creates a disadvantage for the use of multiple drugs and makes the management of these patients difficult $(9,10)$.

Family physicians provide care for all bodily, emotional and social problems of the patients and also manage the acute and chronic problems concurrentlywithin the context of comprehensive care core competency of family medicine. They address the individuals as a whole and use health sources effectively and efficiently (11). Family physicians take each visit as an opportunity for health promotion and preventive measures (12). Lack of a primary care physician was reported to be a risk factor for polypharmacy (7).

The aim of the present study is to investigate the factors that may lead to polypharmacy and to determine the social support status and the risk of depression and anxiety in patients with polypharmacy.

\section{Methods}

This cross-sectional study has been conducted at 3 family medicine clinics in Adana province between January 1, 2018 and February 28, 2018. All consecutive adult patients above 18 years of age, who were registered to these family medicine centers and who have been using 2 or more drugs for longer than 240 days and who had at least one chronic disorder were included in the study. Sociodemographic data of the patients were collected through a form created by the researchers and the participants were divided to two groups as those below or above 65 years of age and those who had a partner or not. Blood pressures 
and anthropometric measurements of the patients were recorded and risk factors for general health were questioned. Participants were questioned for chronic disorders, drug use, number of drugs used and duration of drug use. Afterwards, potential risk factors for polypharmacy and whether the patients were using over-the-counter drugs, knowledge level about medications and drug compliance were questioned with 5 Likert type questions (1: minimum and 5: maximum).

\section{Multi-dimensional Scale of Perceived Social Support} (MDPSS) that was developed by Zimet et al. which consists of 12 7-point-Likert type items (1: I do not agree at all - 7: I completely agree), was used to evaluate social support status (13). The scale has 3 sub-scales as "friends", "family" and "special person". While the possible minimum score is 12 , maximum is 84. Increasing scores indicate better social support. Turkish validity and reliability study of the scale was conducted by Eker et al. (14).

Hospital Anxiety and Depression Scale (HADS) which was developed by Zigmond and Snaith, and which is applied to patients who admit to primary care with somatic disorders was used to evaluate the risk of anxiety and depression. The scale consists of 144 point-Likert type questions scored between 0 and 3 . The cut-off point is $7 / 8$ for anxiety and $10 / 11$ for depression. For both sub-scales, while the possible minimum score is 0 , maximum is 21 . Turkish validity and reliability study of the scale was conducted by Aydemir et al. $(15,16)$.

Statistical Analysis

Descriptive statistics were used for sociodemographic data. Continuous variables were expressed as mean \pm standard deviation and minimum-maximum, categorical variables were expressed as number and percent. The Student's $t$ test and One way Anova test were used for continuous variables and the Chi-square test was used for discontinuous variables to compare the groups. Spearman correlation analysis was used to assess independent variables together that could have an effect on social support status and risk of mental illness of the participants. A two tailed $p$ value less than 0.05 was considered significant.

\section{Results}

Mean age of 393 participants was $60.1 \pm 11.0$ (min 21max 84$)$ years. Of the participants, 149 (37.9\%) were above 65 years of age, 208 (52.9\%) were females, $279(71.0 \%)$ had partners and $114(29.0 \%)$ did not have partners. Ninety-one (23.2\%) participants had low education level, 237 (60.3\%) had moderate and $65(16.5 \%)$ had high education level. According to monthly income, 111 (28.2\%) had low income, 248 $(63.1 \%)$ had moderate income and $34(8.7 \%)$ had high income (Table 1).

Mean systolic blood pressure was $131.2 \pm 21.9 \mathrm{mmHg}$ and mean diastolic blood pressure was $79.7 \pm 13.7$ $\mathrm{mmHg}$. Mean body weight was $80.6 \pm 14.6 \mathrm{~kg}$, mean height was $164.4 \pm 7.8 \mathrm{~cm}$ and mean body mass index (BMI) was $29.8 \pm 5.5 \mathrm{~kg} / \mathrm{m}^{2}$. According to BMI, 66 $(16.8 \%)$ participants were normal weight, 135 (34.4\%) were overweight, 173 (44.0\%) were obese and $19(4.8 \%)$ were morbid obese. Mean waist circumference was below $102 \mathrm{~cm}$ in 122 (65.9\%) males and above $102 \mathrm{~cm}$ in 63 (34.1\%) males. For females, mean waist circumference was below $82 \mathrm{~cm}$ in $63(30.3 \%)$ and above $88 \mathrm{~cm}$ in $145(69.7 \%)$. 
Table1. Socio-demographic characteristics of the

participants

\begin{tabular}{|c|c|c|c|}
\hline \multicolumn{2}{|c|}{ Socio-demographic characteristics $(n=393)$} & \multirow{2}{*}{\begin{tabular}{|l|}
$\mathbf{n}$ \\
185
\end{tabular}} & \multirow{2}{*}{$\begin{array}{l}\% \\
47.1 \\
\end{array}$} \\
\hline & Male & & \\
\hline & Female & 208 & 52.9 \\
\hline \multirow{3}{*}{ Education status } & No education & 91 & 23.2 \\
\hline & Primary/secondary school & 237 & 60.3 \\
\hline & High school/university & 65 & 16.5 \\
\hline \multirow{2}{*}{ Partner } & Yes & 279 & 71.0 \\
\hline & No & 114 & 29.0 \\
\hline \multirow{3}{*}{ Monthly income } & Low & 111 & 28.2 \\
\hline & Moderate & 248 & 63.1 \\
\hline & High & 34 & 8.7 \\
\hline
\end{tabular}

Mean number of chronic diseases was $2.7 \pm 1.2$ (min 1.2-max 8). While 179 (45.5\%) had 1-2 chronic diseases, 177 (45.0\%) had 3-4 chronic diseases and $37(9.4 \%)$ had 5 or more chronic diseases. Mean number of drugs used by the patients was $4.7 \pm 2.2$ ( $\min 2-\max 15$ ) and they have been using the drugs for mean $9.2 \pm 6.2$ years $(\min 1-\max 40$ ). While 52 (13.2\%) patients were using 2 drugs, $153(38.9 \%)$ were using 3-4 drugs and 188 (47.8\%) were using 5 or more drugs (Table 2). The score of using over-thecounter drugs that was evaluated with 5 Likert type questions was found to be $1.9 \pm 1.1$.

Table2. Classification of the participants according to chronic disease and number of drugs used

\begin{tabular}{|l|l|l|l|}
\hline \multicolumn{2}{|l|}{ Number of chronic diseases and drugs used (n=393) } & $\mathbf{n}$ & \% \\
\hline \multirow{2}{*}{ Number of chronic diseases } & $1-2$ & 179 & 45.5 \\
\cline { 2 - 5 } & $3-4$ & 177 & 45.0 \\
\cline { 2 - 5 } & 5 and above & 37 & 9.4 \\
\hline \multirow{2}{*}{ Number of drugs used } & 2 & 52 & 13.2 \\
\cline { 2 - 5 } & $3-4$ & 153 & 38.9 \\
\hline & 5 and above & 188 & 47.8 \\
\hline
\end{tabular}


Comparison of anthropometric measurements, blood pressure values, number of chronic diseases and using over-the-counter medications according to the number of drugs used is presented in Table3. While the number of drugs used increased as age $(F=13.01$, $\mathrm{p}=0.001)$, BMI $(\mathrm{F}=4.080, \quad \mathrm{p}=0.044)$, waist circumference $(F=3.740, p=0.050)$, and number of chronic diseases $(F=99.82, p=0.000)$ increased, and using over-the-counter medications decreased $(F=3.925, p=0.021)$.

Table3. Comparison of anthropometric measurements, blood pressure values, chronic diseases and over-the-counter drug use according to the number of drugs used

\begin{tabular}{|c|c|c|c|c|c|}
\hline & $\begin{array}{l}2 \quad \text { drugs } \\
\text { Mean } \pm S D \\
(n=52)\end{array}$ & $\begin{array}{l}\text { 3-4 drugs } \\
\text { Mean } \pm \text { SD } \\
(n=153)\end{array}$ & $\begin{array}{l}5 \text { and more } \\
\text { drugs } \\
\text { Mean } \pm \text { SD } \\
(n=188)\end{array}$ & $\mathbf{F}^{*}$ & $\mathbf{p}$ \\
\hline Age (year) & $56.5 \pm 13,5$ & $57.8 \pm 10,9$ & $62.9 \pm 9.6$ & 13.01 & $0.000^{t+}$ \\
\hline Weight (kg) & $78.0 \pm 12.4$ & $81.4 \pm 15.2$ & $80.7 \pm 14.7$ & 1.061 & 0.347 \\
\hline BMI $\left(\mathrm{kg} / \mathrm{m}^{2}\right)$ & $28.2 \pm 4.7$ & $30.2 \pm 5.9$ & $29.9 \pm 5.4$ & 4.080 & $0.044^{\dagger}$ \\
\hline Waist circumference $(\mathrm{cm})$ & $91.7 \pm 15.6$ & $95.9 \pm 15.3$ & $96.3 \pm 15.0$ & 3.740 & $0.050^{\dagger}$ \\
\hline Systolic blood pressure $(\mathrm{mmHg})$ & $130.2 \pm 22.3$ & $133.2 \pm 21.8$ & $129.7 \pm 21.9$ & 1.137 & 0.322 \\
\hline Diastolic blood pressure $(\mathrm{mmHg})$ & $79.9 \pm 11.9$ & $80.9 \pm 14.5$ & $78.6 \pm 13.6$ & 1.171 & 0.311 \\
\hline Number of chronic diseases & $1.5 \pm 0,6$ & $2.2 \pm 0,8$ & $3.5 \pm 1,2$ & 99.82 & $0.000^{+\dagger}$ \\
\hline Over-the- counter medication use & $2.3 \pm 1.2$ & $2.08 \pm 1.2$ & $1.8 \pm 1.1$ & 3.925 & $0.021^{\dagger}$ \\
\hline
\end{tabular}

BMI: Body mass index, SD: Standard deviation. ${ }^{*}$ One Way Anova test was used, ${ }^{\dagger} \mathrm{p}<0.05,{ }^{+\dagger} \mathrm{p}<0.01$.

Mean score of the Multi-dimensional Scale of Perceived Social Support (MSPSS) was found to be 55.2 \pm 19.9 . According to the scale, mean score of 'family support' subscale was $25.3 \pm 4.9$, means score of 'friend support' subscale was $14.7 \pm 9.4$ and mean score of

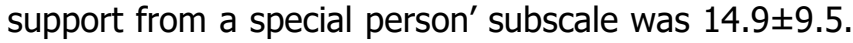
According to Hospital Anxiety and Depression Scale (HADS), mean anxiety score was $6.3 \pm 5.3$ and mean

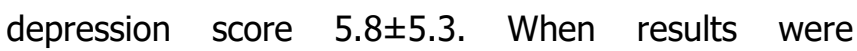
evaluated according to cut-off values, 95 (24.2\%) patients had anxiety risk and $123(31.3 \%)$ had depression risk. 
Table4. The correlation between socio-demographic characteristics and MSPSS and HADS

\begin{tabular}{|c|c|c|c|c|c|c|c|c|c|}
\hline \multicolumn{2}{|l|}{ Scales } & Gender & Age & $\begin{array}{l}\text { Presence } \\
\text { of a } \\
\text { partner }\end{array}$ & $\begin{array}{l}\text { Education } \\
\text { status }\end{array}$ & BMI & $\begin{array}{l}\text { Number } \\
\text { of } \\
\text { chronic } \\
\text { diseases }\end{array}$ & $\begin{array}{l}\text { Number of } \\
\text { medications } \\
\text { used }\end{array}$ & $\begin{array}{l}\text { Duration } \\
\text { of } \\
\text { medication } \\
\text { use }\end{array}$ \\
\hline \multirow{2}{*}{$\begin{array}{l}\text { MSPSS- } \\
\text { Family }\end{array}$} & $r$ & $-0.104^{*}$ & -0.027 & $-0.211^{* *}$ & 0.039 & 0.020 & 0.000 & -0.041 & $-0.139^{* *}$ \\
\hline & $p$ & 0.040 & 0.596 & 0.000 & 0.446 & 0.695 & 0.999 & 0.414 & 0.006 \\
\hline \multirow{2}{*}{$\begin{array}{l}\text { MSPSS- } \\
\text { Friend }\end{array}$} & $r$ & 0.038 & $\begin{array}{l}- \\
0.181^{* *}\end{array}$ & -0.037 & $0.149^{* *}$ & 0.011 & -0.082 & -0.053 & -0.087 \\
\hline & $p$ & 0.449 & 0.000 & 0.461 & 0.003 & 0.835 & 0.104 & 0.292 & 0.086 \\
\hline \multirow{2}{*}{$\begin{array}{l}\text { MSPSS- } \\
\text { Special } \\
\text { person }\end{array}$} & $r$ & 0.030 & $-0.116^{*}$ & -0.032 & 0.067 & 0.013 & -0.072 & -0.039 & -0.075 \\
\hline & $\mathrm{p}$ & 0.555 & 0.022 & 0.526 & 0.182 & 0.802 & 0.154 & 0.435 & 0.138 \\
\hline \multirow{2}{*}{$\begin{array}{l}\text { MSPSS- } \\
\text { Total }\end{array}$} & $r$ & 0.018 & $\begin{array}{l}- \\
0.149^{* *}\end{array}$ & -0.094 & $0.110^{*}$ & 0.019 & -0.075 & -0.059 & $-0.111^{*}$ \\
\hline & $p$ & 0.721 & 0.003 & 0.064 & 0.029 & 0.709 & 0.137 & 0.240 & 0.028 \\
\hline \multirow[t]{2}{*}{ HAD-A } & $r$ & $0.308^{* *}$ & $\begin{array}{l}- \\
0.243^{* *}\end{array}$ & $0.230^{* *}$ & $-0.101^{*}$ & 0.056 & 0.087 & 0.062 & 0.005 \\
\hline & $p$ & 0.000 & 0.000 & 0.000 & 0.046 & 0.268 & 0.086 & 0.219 & 0.924 \\
\hline \multirow[t]{2}{*}{ HAD-D } & $r$ & $0.264^{* *}$ & $\begin{array}{l}0.186^{* *} \\
-\end{array}$ & $0.289^{* *}$ & $-0.137^{* *}$ & 0.013 & 0.098 & 0.059 & -0.007 \\
\hline & $p$ & 0.000 & 0.000 & 0.000 & 0.007 & 0.805 & 0.053 & 0.244 & 0.894 \\
\hline
\end{tabular}

BMI: Body mass index, MSPSS: Multi-dimensional Scale for Perceived Social Support, HADS-A: Hospital Anxiety and Depression Scale-Anxiety, HADS-D: Hospital Anxiety and Depression Scale-Depression. r: Spearman's rho, p: Significance (2-tailed). ${ }^{*}$ Correlation is significant at the 0.05 level (2-tailed), ${ }^{* *}$ Correlation is significant at the 0.01 level (2-tailed).

The correlation between socio-demographic characteristics, BMI, the number of chronic diseases, the mean number of medications used, duration of medication use, and MSPSS and HADS was examined. According to MSPSS, 'family support' was low among females $(r=-0.104, p=0.040)$. 'Friend support' $(r=-0.181, p=0.000)$, 'support from a special person' $(r=-0.116, p=0.022)$ and total score $(r=-0.149$, $\mathrm{p}=0.003)$ decreased as age increased. 'Friend support' $(r=-0.149, p=0.003)$, and total score $(r=-0.110$, $\mathrm{p}=0.029$ ) increased as level of educational increased. 'Friend support' $(r=-0.139, p=0.006)$ and total score $(r=-0.111, \quad p=0.028)$ decreased as duration of medication use increased. According to HADS, the risk 
of anxiety and depression was significantly higher in females ( $r=0.308, p=0.000$ and $r=0.264, p=0.000$ ) and who had no partner $(r=0.230, p=0.000$ and $r=0.186, p=0.000)$. The risk of anxiety and depression was found to decrease as age increased $(r=-0.243$, $p=0.000$ and $r=-0.137, p=0.007)$ and as the level of educational increased $(r=-0.101, p=0.046$ and $r=-0.137, p=0.007)($ Table 4).

\section{Discussion}

In this cross-sectional study, we have investigated the factors that could be effective on multi-drug use in adult patients who are being followed-up at primary care and also social support and anxiety, depression risk in these patients. The gradually aging population brings increased number of chronic diseases together and thereby multi-drug use. So, most of the previous studies in this issue have been conducted with patients above 65 years of age (7-12). Differently from most previous studies, we have evaluated multi-drug use in all patients above 18 years. Mean age of the participants was $60.1 \pm 11.0$ years and $244(62.1 \%)$ were below 65 years.

In our study, the mean number of chronic diseases was $2.7 \pm 1.2$ and the mean number of medications used was $4.7 \pm 2.2,13.2 \%$ of the participants were using 2 medications, $38.9 \%$ were using 4 medications and $47.8 \%$ were using 5 or more medications. In the study of Kostev et al. conducted with patients above 60 years who were admitted to family physicians, mean number of prescribed medications was found to be 4.2 (17). Morin et al. have reported this number as 4.6 in their study conducted with individuals 65 years and over in Switzerland (18). In a study from Thailand, of 2806 patients who were above 65 years of age and who have admitted to primary care, $27.5 \%$ were found to have been using $\geq 5$ medications and $43.7 \%$ were found to have been using potentially inappropriate medications (8). In the study of Kutsal et al. investigating multi-drug use in individuals above 65 years of age, $17 \%$ of the participants were using 2 medications, $19.2 \%$ were using 3 medications and $38.2 \%$ were using 4 or more medications (9). In a cross-sectional study conducted with 43 general practitioners and579 patients in Italy, $13.4 \%$ of the patients over 75 years of age, were on therapy with $\geq 8$ drugs (19).

Kardas et al. have analyzed national cohort of 38 million Polish citizens, and found that the prevalence ofpolypharmacy was $11.7 \%$ in 2018 and $11.6 \%$ in 2019. Theprevalence of polypharmacy was detected to increase, reaching $56.0 \%$ in those aged $80+$ in 2018 , and $55.0 \%$ in 2019. Altogether, polypharmacy was present in $43.1 \%$ in 2018, and $42.1 \%$ in 2019 among those aged above 65 years. In the citizens aged below 20 years, polypharmacy was found to be in the ratio of $0.9 \%$, and $0.8 \%$ in 2018 and 2019, respectively (20). In our study, 244 of the patients were under 65 of age and the ratio of multi-drug use was found to be $43,0 \%$ and 149 of the patients were over 65 of age and the ratio of multi-drug use was found to be $57,7 \%\left(X^{2}=9,495, p=0,009\right)$.

The frequency of chronic diseases which often requires the use of more than one drug, increases with aging. Therefore, multiple co-morbidities are an important etiological factor for polypharmacy. Midao et al. reported that the number of chronic diseases is directly related to polypharmacy (21). Li Min Lim et al. reported in their study conducted with 1256 individuals above 55 years of age who have been using a medication for longer than 3 months that the risk factors associated with increasing medication use were increasing age, Indian ethnicity, male, having a higher number of comorbidities (22). The study of Slater et al. confirms that increasing age and the presence of chronic health conditions are associated with polypharmacy, but also that obesity and lower wealth 
are significantly associated with polypharmacy (23). The present study has revealed similar results indicating that increased age, BMI, waist circumference and the number of chronic diseases increased the number of medications used.

In the study of Unsar et al. conducted with 912 patients above 60 years of age who were registered to family medicine clinics in Edirne province, the authors found that the mean number of medications used daily was $2.8 \pm 2.5$, the mean MSPSS score was $60.6 \pm 17.1$ and the mean Geriatric Depression Scale (GDS) was 12.2 \pm 7.7. There was a significant negative correlation between the age, the numbers of drugs taken daily and MSPSS scores (24). In our study, a negative correlation was detected between total MSPSS score and age, and a positive correlation was detected between total MSPSS score and level of education.

Wongpakaran et al. investigated the prevalence and predictors associated with polypharmacy in the elderly at primary care clinics and psychiatric clinics of tertiary care hospitals within the DAS program (açılımı?) which was funded by National Research Council of Thailand. In this study, anxiety disorder and depressive disorder were found to be associated with higher medication (25). In our study, the risk of anxiety and depression was significantly higher in women and who had no partner. On the other hand, the risk of anxiety and depression decreased as age and level of education increased. There was no correlation between polypharmacy and anxietydepression risk in our study.

In conclusion, the prevalence of polypharmacy among adult patients in primary care clinics in Turkey is high. Significant physical and mental problems occur in individuals who use multiple drugs, especially in the elderly. Our findings revealed that predictors of polypharmacy include age, BMI, waist circumference and number of chronic diseases. Primary carephysicians play a pivotal role in medication review and prescribing medications. They should be aware of those predictors when prescribing additional medications, the indication should be clearly specified and all the aspects should be taken into consideration.

\section{Ethics approval and consent to participate}

This study was approved by the Health Sciences University Adana City Training and Research Hospital Clinical Research Ethics Committee on November 28, 2017 (No 136). All procedures performed in studies involving human participants were in accordance with the ethical standards of the institutional and/or national research committee and with the 1964 Helsinki declaration and its later amendments or comparable ethical standards. All participants signed informed consent forms.

\section{Conflict of interest}

The authors declare that there is no conflict of interest. 


\section{References}

1. Çurgunlu A. Polifarmasi kavramı. Akademik Geriatri Dergisi 2011; 2: 68-70.

2. Veehof $L$, Stewart $R$, Haaijer-Ruskamp $F$, Meyboom-De JB. The development of polypharmacy: A longitudinal study. Family Practice 2010; 17: 261-267.

3. Zarowitz BJ, Stebelsky LA, Muma BK, Romain TM, PETERSON EL. Reduction of high-risk polypharmacy drug combinations in patients in a managed care setting. Pharmacotherapy 2005; 25: 1636-1645.

4. Papapetrou I, Jelastopulu E, Symeonidou E, Kleridou M, Floridou D, Charalambous G. Investigation of polypharmacy and rational prescribing in elderly patients in a health centre of Nicosia. Cyprus. China-USA Business Review 2012; 11: 1587-1594.

5. Erdinçler DS. Yaşıda akılcı ilaç kullanımı. İ.Ü. Cerrahpaşa Tıp Fakültesi Sürekli Tıp Eğitimi Etkinlikleri 2010; 69: 9-31.

6. Slone Epidemiology Center. Patterns of medication use in the United States. A Report from the Slone Survey, Boston University; 2006. Retrieved Apr 2018 from: http://www.bu.edu/slone/files/ 2012/11/SloneSurveyReport2006.pdf

7. Halli-Tierney $A D$, Scarbrough C, Carroll D. Polypharmacy: Evaluating Risks and Deprescribing. Am Fam Physician. 2019;100(1):32-38.

8. Vatcharavongvan $P$, Puttawanchai V. Elderly Patients in Primary Care are Still at Risks of Receiving Potentially Inappropriate Medications. J Prim Care Community Health. 2021 Jan-Dec; 12:21501327211035088. PMID: 34315288.

9. Asma S, Gereklioğlu Ç, Korur AP, Erdoğan AF. Multimorbiditesi olan yaşlı hastalarda çoklu ilaç kullanımı: aile hekimliğinde önemli bir problem. TJFMPC 2014; 8 (1): 8-12

10. Brünn $R$, Müller $B S$, Flaig $B$, KellermannMühlhoff $P$, Karbach $U$, Söling $S$, Muth $C$, van den Akker $M$; AdAM Study consortium. "I must, and I can live with that": a thematic analysis of patients' perspectives on polypharmacy and a digital decision support system for GPs. BMC Fam Pract 2021;22(1):168. doi: 10.1186/s12875-02101517-6. PMID: 34418964.
11. Marx G, Püsche K, Ahrens D. Polypharmacy: a dilemma in primary care? Results of group discussions with general practitioners. Gesundheitswesen 2009;71 (6):339-48.

12. Allen J, Gay B, Crebolder H, Heyman J, Svab I, Ram $P$, editors. Aile Hekimliği Avrupa Tanımı WONCA AVRUPA 2005, Türkiye Aile Hekimleri Uzmanlık Derneği Yayınları-4, Nisan 2011: pp 13-14.

13. Zimet GD, Dahlem NW, Zimet SG, Farley GK. The Multidimensional Scale of Perceived Social Support. Journal of Personality Assessment, 1988; 52(1): 30-41.

14. Eker D, Arkar H, Yaldız H. Çok Boyutlu Algılanan Sosyal Destek Ölçeğinin gözden geçirilmiş formunun factor yapısı, geçerlik ve güvenirliği. Türk Psikiyatri Dergisi 2001;12 (1):18-25.

15. Zigmond AS, Snaith PR. The Anxiety And Depression Scale. Acta PsychiatrScand 1983; 67 (6): 361-70.

16. Aydemir Ö, Güvenir $T$, Küey $L$, Kültür $S$. Hastane Anksiyete ve Depresyon Ölçeği Türkçe formunun geçerlilik ve güvenilirliği. Türk Psikiyatri Dergisi 1977; 280-287.

17. Kostev K, Jacob L. Multimorbidity and polypharmacy among elderly people followed in general practices in Germany. Eur J Intern Med 2018 Sep; 55:66-68.

18. Morin L, Johnell K, Laroche M-L, Fastbom J, Wastesson JW. The epidemiology of polypharmacy in older adults: register-based prospective cohort study. Clin Epidemiol 2018;10:289-298.

19. Piccoliori G, Mahlknecht $A$, Sandri M, Valentini M, Vögele A, Schmid S, Deflorian F, Engl A, Sönnichsen A, Wiedermann C. Epidemiology and associated factors of polypharmacy in older patients in primary care: a northern Italian cross-sectional study. BMC Geriatr. 2021 Mar 20;21(1):197. PMID: 33743582.

20. Kardas $P$, Urbański $F$, Lichwierowicz $A$ et al. Prevalence and Age Structure of Polypharmacy in Poland: Results of the Analysis of the National Real-World Database of 38 Million Citizens. Front Pharmacol. 2021;12:655364. PMID: 33935769.

21. Midao L, Giardini A, Menditto E et al. Polypharmacy prevalence among older adults based on the Survey of Health, Aging and Retirement in Europe, Archives of Gerontology and Geriatrics2018; 78, 213-220. 
22. Lim LM, McStea M, Chung WW et al. Prevalence, risk factors and health outcomes associated with polypharmacy among urban community-dwelling older adults in multiethnic Malaysia. PLOS ONE 2017;12 (3): e0173466.

23. Slater $N$, White $S$, Venables $R$, Frisher $M$. Factors associated with polypharmacy in primary care: a cross-sectional analysis of data from The English Longitudinal Study of Ageing (ELSA). BMJ Open. 2018;8(3):e020270.

24. Unsar S, Dindar İ, Kurt S. Activities of daily living, quality of life, social support and depression levels of elderly individuals in Turkish society. J Pak Med Assoc 2015; 65( 6): 642-646.

25. Wongpakaran N, Wongpakaran T, SirirakT et al. Predictors of polypharmacy among elderly Thais with depressive and anxiety disorders: findings from the DAS study. BMC Geriatrics 2018;18:309. 